\title{
Mock Trial: Who Is Responsible for Access to Emerging Technology, Specifically Endoluminal AAA Surgery?
}

\author{
MODERATOR: Hugh E. Scully, M.D. ${ }^{1}$ \\ PANELISTS: $\quad$ Wayne R. Tanner, M.D. ${ }^{2}$ \\ Frank J. Veith, M.D. ${ }^{3}$ \\ Mr. Scott Rowand 4 \\ Philip C. Hébert, M.D. 5 \\ Hon. Madame Justice M. MacDonald 6
}

\begin{abstract}
The case is a 75-year-old male patient with a large abdominal aortic aneurysm (AAA). He has a very high operative risk because of associated cardiac disease, and is turned down for elective repair. One month later, the aneurysm ruptures and the patient dies. The family reads in the newspaper that similar AAAs can be repaired using minimally invasive techniques, that are only available in Canada on a compassionate basis because of the high cost. The family decides to initiate a civil suit. Presentations are heard from the defense (vascular surgeon), prosecution expert witness, hospital administration, and an ethicist. At the conclusion, a legal judgment will be provided by a justice of the Supreme Court of Ontario. Who is responsible?
\end{abstract}

Keywords Endovascular, aneurysm, stent

Perspectives in Vascular Surgery and Endovascular Therapy, Volume 14, Number 1, 2001. Address for correspondence and reprint requests: Peter Gloviczki, M.D., Division of Vascular Surgery, Mayo Clinic, 200 First St. SW, Rochester, MN. ${ }^{1}$ Division of Cardiovascular Surgery, Toronto General Hospital, Toronto, Ontario; ${ }^{2}$ Don Valley Medical Center, Toronto East General Hospital, Toronto, Ontario; ${ }^{3}$ Department of Surgery, Division of Vascular Surgery, Montefiore Medical Center, Albert Einstein College of Medicine, Bronx, NY; ${ }^{4}$ Hamilton Health Sciences Corporation, McMaster University Health Center, Hamilton, Ontario; ${ }^{5}$ Sunnybrook Health Sciences Center, Toronto, Ontario, Canada; ${ }^{S}$ Superior Court of Justice, Toronto, Ontario. Copyright (c) 2001 by Thieme Medical Publishers, Inc., 333 Seventh Avenue, New York, NY 10001, USA. Tel: +1(212) 584-4662. 1531-0035,p;2001, $14,01,129,162, \mathrm{ftx}, \mathrm{en} ; \mathrm{pvs} 00112 \mathrm{x}$. 
Introduction by Peter Gloviczki: I would like to introduce Dr. Hugh Scully, who is well known to many of you, but perhaps wearing one of his different hats. Hugh is a Professor of Surgery at the University of Toronto and a senior cardiac surgeon and Professor of Surgery at the University of Toronto. You may be more familiar with one of his other hats, that is, as the current President of the Canadian Medical Association. He has other prominent leadership positions and has been the past President of the Ontario Medical Association and the Canadian Cardiovascular Society. I am very grateful to Hugh for agreeing to moderate and supervise this afternoon's mock trial.

Modevator: Peter asked me to be included because of my involvement when I was president of the Canadian Cardiovascular Society and the mock trial that was held about a cardiac surgical case. Somewhat different, but the principles are very much the same. So, we thought we would put together a panel and try to explore it from different facets. Of course, the background is the environment in which we're having the discussion is that the residents of Ontario, indeed all of Canada, expect that physicians and hospitals, and vascular surgeons who are hospital based in large part, will provide the best available treatment, based on the highest standards and current medical knowledge and practice and using the latest innovations and technology. That is the backdrop against which the discussion takes place. I can tell you that health care is the principal subject engaging conversation these days. I just finished a whole series of representations on behalf of the profession to the government of Canada and am now having meetings on a weekly basis with Allan Rock, Federal Health Minister, the last of which was 1 $1 \frac{1}{2}$ hours yesterday, talking about where things are going from here. As you recall, if you read the papers, the amount of allocation in the federal budget with respect to the federal share of health care was far short certainly of what I had requested on your behalf and on the behalf of the patients of Canada, and far short of the expectation that was there on the part of many others. Now we are getting into the political rhetoric between the Prime Minister and the Premiers and between the Ministers of Health. Rock will be meeting March 30 and 31 with his counterparts across the country. I will then be on a steering committee on behalf of the profession with the Ministers, with another targeted meeting on May $\mathrm{l}$ and 2, with a view of having a report available for the Premiers in June. Word on the street is that there will be an election where health care will be a major issue. So, that is the background.

Also, the economic climate in health care at the dawn of this new millennium is very different than in the boom times of the early 1980s. The collective debts of Ontario hospitals are approximately $\$ 2.2$ billion today. Hospitals and physicians have had their funding constrained; one of our panelists is on the negotiating committee on their behalf. I had the experience, sometimes pleasant and sometimes not, of being initially on the committee and then the chief negotiator on your behalf in the middle 1980s for problems of physician 
compensation, when times were better. So, if you can get that kind of a deal you will be a hero. But, the issue is that resources are constrained. Hospital budgets have been cut in this province; physician fees are capped. In terms of technology, when it comes to computed tomography (CT) scanners, magnetic resonance imaging (MRI), and "lithryptors," we ranked 16th, 18th, and 21st in the developed world; we are at the same level as Turkey. One of the issues today is allocation of resources, availability of resources that are known to be effective, either for diagnosis or in this case treatment in the patients' interests and where that places the various players. It is an interesting challenge. What is your duty as a physician, as an advocate for the individual patient? What is your duty to treat, and what is your fiduciary responsibility, what information do you need to share, what kind of plea bargaining do you need on behalf of your patient with the hospital or the government in the patients' interests?

Standards of law, as they apply to the future responsibility, are in the view of some, increasingly at odds with the reality of a possibility of practice, and that is part of the reason for today's discussion. What is the responsibility of the hospital? In British case law and American case law, not so far as yet in Canadian case law that I am aware of, there have been from time to time suits registered against health authorities responsible for providing insured services where physicians have advocated (and it is a matter of record), for necessary equipment for treatment for their patients. The authorities have been found liable, not the physicians. That is another issue. We will have, with his usual perfect timing, an entrance of a hospital representative, Mr. Scott Rowand, who will take the case of the hospital, caught in the squeeze between physicians making the demands and the government restricting the budget or providing the money for the budget overall. We will have some discussion about the ethics of making resource allocation for surgery in this day and age.

Finally, we will have, not for the record but for discussion, a legal opinion about some of the arguments that have been presented by the protagonist defendants and antagonists at the front of the room. So, that is the background. What I want to do today is perhaps cite to you some documents, and Peter and I can make these available, because they are very interesting reading. First is "Have Funding Cutbacks Changed the Legal Standard of Care?" There is much legal language, but there are some very important principles in the document. Second is "The Doctor's Dilemma, Fiduciary Duty and Fiscal Restraints." That is in two parts; a part from the College of Physicians and Surgeons, Ontario, and a part from a lawyer who is from one of the respected firms who does much of this work. Then there is another one on hospital liability in the era of declining health resources - interesting reading for those of you who have senior responsibility in hospitals in making allocation decisions. Should you as physicians be involved in that kind of a process? Finally, an overview document, "Resource, Allocation and Accountability in Health Care." I would recommend those to you for reading at some stage because it 
is certainly the backdrop against which the discussion takes place, and increasingly I think we are going to be seeing some case law.

I think we have an interesting panel. My role will be to introduce the panelists and maybe provoke some discussion. We will go through some of the details, much to the great chagrin of the clinicians in the room. However, today we have some arguments for you, Scott, that weren't mounted before.

First defendant, the person who has been charged, is Wayne Tanner. You have in your case outline the actual case. Do I need to read that to you? The first person I call on is Wayne, who is a vascular surgeon at Toronto East General Hospital, very well known to most people in the room and who doesn't need an introduction. Wayne has been very active on behalf of specialists generally, and as I say represents specialists in the negotiations with the government of Ontario.

Dr. Tanner: Unaccustomed as I am to being in the eye of the hurricane, I would like to thank Peter Kalman for placing me in this position today and congratulate him while I still have a chance on another successful symposium.

These days with all my activities, my wife never quite knows what I am doing on any given day when I walk out of the house, so she has taken to evaluating my activities based on what I am wearing. When I leave the house in jeans and a T-shirt I am probably going to the hospital to work; but, when I dress in a suit or some equivalent, I am probably going down to meet with the government. You can't really take those observations entirely to the bank, but they are fairly accurate. Today when she saw me getting into a suit she assumed I was off to negotiate and I said, "No, I am going to a vascular meeting." I gave her a little rundown of what I was to do. She said, "Well, that should be quite a day," and she gave me a kiss and said, "Well, I am just going to go clean out your closets because I suspect you won't be coming back." So, that is sort of guilty until proven innocent, I guess.

For purposes of this presentation, I will wear none of the hats that Hugh alluded to, and I am simply a hard-working, overworked, underpaid, underappreciated surgeon, working in the underfunded trenches of Ontario.

So, the patient we are dealing with here today is a 75 -year-old man who was sent to me for a second vascular opinion. He had already been evaluated at one of the downtown teaching hospitals and told that his situation was too high risk for surgery. It is not infrequent in the world of vascular surgery, and I know there are some nonmedical people in the audience, so it is not infrequent for people, particularly if they have been given especially bad or negative news, to seek second and sometimes third opinions. So, that is what happened in this case. This patient came with a known $7-\mathrm{cm}$ infrarenal aortic aneurysm. It had been picked up by GP; he had been referred to someone who had done a CT scan and, in fact, an angio. So, he came to me with both of those in hand. 
I have only his angiogram here today on a slide, and I'll put it up in a second. He had been turned down because of multiple medical problems. All surgeons in the audience know that physiological rather than chronological age is far more important a determinate than who is an operative candidate and who isn't. So, based on the fact that he was 75 years of age, I would not have ruled him out. His associated problems, unfortunately, made him a very difficult candidate. He had long-standing atherosclerotic heart disease with a known grade IV ventricle, intermittent bouts of congestive heart failure, and at least two admissions to the hospital for congestive failure in the preceding 6 months: unstable and really only partially treatable angina. Previous coronary angiography showed an inoperable state of affairs, chronic obstructive lung disease on home O-2, and he was largely confined to one or two rooms of his house, except when going out to doctor appointments. His principal past surgical history was for a perforated peptic ulcer some years ago with a laparotomy, from which he subsequently developed a large reducible, only minimally symptomatic ventral hernia.

Well, I listened to all of this and afforded him and his family the courtesy of reviewing the tests with them and so on. The aneurysm on CT was $7 \mathrm{~cm}$, and the angio, which I probably wouldn't have done at all, had been done elsewhere, and he had it with him; this is it. It shows an aneurysm, the luminal size would not reflect the overall size. You can see there is a good neck and quite normal iliacs. In either event his cardiologist, prior to my seeing him, had given him a 50\% mortality with any intervention of any kind, minimum. To me it simply confirmed the first surgical opinion, that I didn't think he would withstand an operation. I felt he had several concomitant lifethreatening conditions, any of which could kill him at any time, the least of which was probably this aneurysm. So I graciously declined. They seemed grateful for this, seemed grateful with the fact that the opinion meshed with the first, in particular because they had some respect for the initial surgeon. So they now had two similar opinions, similar stories that weren't flying in the face of one another, even remotely. I felt they went away happy. I sent off the appropriate consulting letters, copies to all the appropriate people and so on, and that was that.

About a month later one of the family members phoned my office to report that the patient had ruptured his aneurysm exactly as I predicted he would, although I hadn't predict when, and died en route to the hospital; he therefore had been buried, without any interventions. About 6 months after that I was served with notice of a civil litigation against me, and in the initial paperwork that came with that, the discoveries and so on, they cite the principal reason for the lawsuit being that I had failed to inform them of alternate forms of therapy that might have been available for this man-specifically endovascular or interluminal aortic grafting, which they had read about in the newspapers and their young technofiend son had been reviewing on the 
Internet. They seemed to think that had he had this procedure, he would have been around enjoying, such as it was, his life and, therefore, they were suing me for this. That is the presentation of the case. I will say I am not sure how they want me to proceed here. My specific defense in this case is (1) I didn't take it upon myself to address the option of endovascular grafting with this patient because they didn't ask, they didn't bring it up; (2) in addition, they had come from a hospital where I knew a couple of experimental grafts had been done, and it occurred to me that if they considered him a candidate they might have discussed it with them. But, the broader issue is that for all intents and purposes this procedure is not available to the general public in this province, for that matter, not in this country. Even in other countries where it is more widely available it still remains as a trial and somewhat an experimental procedure. I am familiar enough with the literature and with what is going on to recognize that the cost associated with this is insurmountable. The problems are not inconsequential, and I didn't feel that even suggesting this to the family was appropriate in that among other things it would have given them incredible false hope-because in my experience I have never really known anyone who has gone on locally to get through the system successfully. Having said that I know there are anecdotal cases and I know the cases are increasing. There is no funding; as far as I know it simply is not available. In our own hospital specifically we have never approached this subject. We are several echelons back in technology. I think we are miles away from this, if it ever becomes widely acceptable. So, that is how I left it. Basically I know it is not available and I didn't feel that presenting them with that was appropriate, although I would have discussed it in detail had they brought it up.

Modevator: Okay, so we have a surgeon who rendered a second opinion in an institution that didn't have the technology, with a first opinion rendered in an institution where it had been used on an experimental basis. In any event, you didn't discuss this as a possibility. We are all facing this all the time, more and more, where members of the family come in with having researched the Internet at a time when medical knowledge is doubling every 18 months, and it is a real challenge. That is a whole different subject in itself. A suit has been entered against Dr. Tanner as a surgeon for failing to inform or perhaps provide information that would allow the family to pursue a different option. Well, the next presentation is going to be from an individual I think is well known to this Society, Frank Veith. He is the Professor of Surgery at Albert Einstein College of Medicine and Head of vascular surgery at the Montefiore Medical Center in New York. Indeed, he is one of the world's leading authorities on endoluminal abdominal aortic aneurysm repair. He graduated from Cornell and is now associated with the Montefiore Medical Center, and he has held positions in every national Vascular Society and many international societies. In 1995, he was elected president of the Society for Vascular Surgery and has worked hard and long to establish vas- 
cular surgery as a true, free-standing specialty in and of itself. Frank is here today to take the counterview and talk about this approach to treatment of aneurysms.

Dr. Veith: Because this is a court proceeding I can't thank Peter Kalman for inviting me to this meeting or say how good I think it is; I guess that is a given. As the one who is to build the case for the prosecution, I could present an emotional appeal to you that the defendant be crucified financially. I'm not going to do that. What I would like to do in the next few minutes is give you some factual background about endovascular grafts for the treatment of aneurysms and then allow the process to proceed and allow the judge to make a decision on the basis of what I think are the facts as we know them today. Our group was the first to do endovascular grafts for an aneurysm in North America. We probably have the largest experience, and our program is now in its 9 th year. We have now used 581 endovascular grafts in over 300 patients. Well over 200 of these have been for aortoiliac aneurysms. I will review our experience with these cases so you can make your judgment. At the beginning, because of the experimental nature of this procedure, we chose patients very similar to the one being considered today, although I must say we never had a patient with such good anatomy. His aneurysm was very favorable for endovascular repair. We have not had many quite that easy. However, we have had many patients who were as sick, or sicker, than the one presented. In the beginning we chose patients who had a very threatening vascular situation, together with a comorbid illnesses such as you have heard, and often a difficult anatomic situation, such as a patient who has a large unreducible ventral hernia, which I guess the patient today had-certainly not appetizing for standard open surgery. These are some of the grafts we use. This is the original Parodi graft, a first-generation graft. This is the EVT graft. These are the grafts we are currently using: a variety of bifurcated, mostly modular grafts made by several commercial firms. For easy patients, technically easy patients, we would choose one of these industrymade bifurcated grafts. When one of these grafts is not suitable because of technical limitations, we use our own Montefiore Endovascular Grafting System grafts. We originally used these MEGS grafts in an aortoiliac configuration, and they didn't work very well with the stent placed here below the renals. They didn't because we rarely had necks that were as nice as the one in this patient. No matter what we did, we never could get the length measurement right, so it was either too long or too short. We therefore have moved to the current iteration of our graft, in the hard-to-fix patients. The stent, the open portion, goes across the renal arteries to assure good fixation in the solid part of the aorta; the graft then begins just below the renal arteries and extends down to the femoral introduction site where we cut off the excess graft and do an endovascular anastomosis. We also coil embolize the branches of the ipsiteral hypogastric artery, which allows us to treat large iliac aneurysms that the patient did not have. We also must occlude the opposite 
iliac artery and perform a fem-fem bypass. This is clearly a big operation, although it can be done in a minimally invasive fashion, and it does work. It is not our first choice for an easy patient, such as the one shown today. However, with the availability of the MEGS grafts, in a 1-year period we were able to endovascularly treat $80 \%$ of all the aneurysms we saw in that year. About half of them received a commercially made device, about one third were treated with our MEGS device, and $20 \%$ with no necks or very bad iliac arteries had an open repair. That figure is probably too high. We probably were doing cases endovascularly that should have been treated by standard surgery, but that is what the future may well hold. Here is one example. This is a patient in another hospital with a very unattractive neck measuring 120 degrees in angulation, a double-bubble aneurysm. He had been operated on open at the other institution. (You see the clips here.) He suffered a cardiorespiratory arrest. They closed him and resuscitated him. He spent 3 weeks in an ICU and then he came to us. We did an endovascular repair with some difficulty but nevertheless accomplished it. The patient did well and went home after 3 days. He is now 2 $\frac{1}{2}$ years out and still doing nicely with his aneurysm excluded and all aortic flow going through the graft. Another case, also inoperable: this patient had very bad heart disease, analogous to the one presented by Dr. Tanner. He also had this large false aneurysm where a prior aortofem and aortoiliac graft had dehisced at the iliac anastomosis. He had a smaller proximal anastomotic false aneurysm and he was on hemodialysis. He actually presented with signs of rupture. We treated him rather urgently, and here you see all the flow going through the graft, which is in the left limb of the old aortofemoral graft. His aneurysm was completely excluded. He lived for about $2 \frac{1}{2}$ years and then died of his intercurrent morbidities.

This is an "apple on a string," aneurysm similar to the one you have seen today. This patient received an EVT graft, which we thought fixed him perfectly; the hooks right here below the renals and right here near the bifurcation. We thought we had a success. Interestingly, success in this field, early success, does not always translate into late success, and about $1 \frac{1}{2}$ years afterward the hooks on this particular graft became displaced from the neck of the aneurysm, the graft popped out, and the aneurysm was repressurized. We treated him with one of our MEGS devices, placed within the old graft, and this particular patient had his leak fixed. He is now 4 years after the leak, $5 \frac{1}{2}$ years after the original EVT graft, and still doing pretty well.

We have also used industry-made bifurcated devices both in high- and lowrisk patients. They work quite well. Here is one patient, not totally simple, a big aneurysm. Also a common iliac and a hypogastric aneurysm, treated fairly simply with a bifurcated device. Here is the patient on the morning after operation. He actually looks better than his two surgeons. But, again, we thought we had a success. A year later his aneurysm enlarged again; his graft had become displaced out of the iliac on one side. We were able to treat him 
endovascularly; he is now another 2 years out from the second operation, continuing to do well. Again, early success doesn't always translate into late success.

Iliac aneurysms: we don't have time to go into these, but they come in a variety of sizes and shapes, all of which are fixable through endovascular means. We currently believe that, because these aneurysms are rather difficult to fix surgically, endovascular grafts are already a better way of treating iliac aneurysms, although I am sure there are many who would disagree with this view.

In our total of some 230 patients with aortoiliac aneurysms, we have had a $5 \%$ death rate. Many of the patients were quite sick and died from their underlying comorbidities or multiorgan failure after a fairly complicated procedure. There have been a few who died from their underlying end-stage heart disease. So, just doing these procedures doesn't guarantee they are going to be successful. They can fail, and it is important in considering all this to keep that in mind.

So, where do we think this treatment currently stands? At present, as being appropriate for treating patients, still investigational but not experimental, we think high-risk patients and those with hostile abdomens, such as the one presented today, are a perfect place to continue to use these endovascular grafts. We use them also in secondary situations where a prior open surgical procedure has failed. We also like to use them in iliac aneurysms because we think the surgery is difficult. We don't know what their value in good-risk patients is going to be because late problems occur and we need longer-term results than even we have.

Now, I am going to spend a few minutes, because this is a medical meeting, telling you about what I think is the most exciting development for us, and that is the use of these devices for ruptured aneurysms. In this entity, there is no question that the surgical treatment results are poor. There is at least a $50 \%$ mortality, probably higher with standard surgical treatment, at least in our hospital and most other ones. Because our device can be available and stored on the shelf, and because one size fits almost all patients, we have explored the use of this device to treat ruptured aortic aneurysms for a number of years. Here is one such patient with a contained rupture of a false aneurysm. He was totally inoperable with an ileostomy and many abdominal scars, a bad heart. Here he is fixed. This patient lived for about 3 years with resolution of all his signs and symptoms. This is another early patient, on home oxygen with chronic lung disease, a ruptured aneurysm, not a simple one, with a large iliac aneurysm. Here she is fixed with the aneurysm excluded. She is alive, $2 \frac{1}{2}$ years later and actually was in the hospital only 3 days, although her operation was very complex and long to perform. Here is another case. This is the most dramatic one we have had among the ruptures: a 71-year-old man on oxygen, a poor ejection fraction. (Dr. Tanner, I would say your patient couldn't be much worse than this.) In addition, our 
patient was on chemotherapy for leukemia, so he didn't have any platelets. He was admitted to another hospital for an acute pneumonia where he promptly ruptured his aneurysm as shown by this CAT scan. He was sent to us in shock; the ride took about 2 hours. He arrived, promptly dropped his $\mathrm{B} / \mathrm{P}$ to 50 , and had a respiratory arrest. We took him directly to the operating room, where we let him be hypotensive. This slide shows an angiogram, and there is no extravasation of dye. We were able, keeping him hypotensive, to fix the aneurysm with an endovascular graft and, despite his comorbidities, he survived. His rupture resolved, and he went home 5 days later. Thus, based on the high morbidity and mortality for standard surgery in ruptured aneurysms, we believe that endovascular grafts may be a better treatment than standard surgery, and we are currently exploring this premise as aggressively as we can.

The objection that delay until control is obtained (which is often voiced by surgeons) we think is not valid because many patients remain stable for a fairly long time after their aneurysm ruptures. We also believe that hypotension is a great hemostatic agent, so we leave the patients in shock as long as they are talking. We don't worry about their blood pressure. However, a few patients have stopped talking and dropped their blood pressure even lower, so we have developed a system for inserting a brachial wire and a balloon to occlude the thoracic aorta. We only use this system when patients really crash. Here is one such patient with a free rupture, extravasation, a balloon inserted in the thoracic aorta, and the endovascular graft placed. This patient survived.

We have used this approach now in 25 patients with ruptured abdominal aneurysms. In all, the grafts were successfully inserted. Only 2 of these 25 patients died. Five of the patients, when we got the arteriogram, required an open operation. All five of those patients survived. Twenty were treated with an endograft and 18 survived. Thus, we feel this is a possible better way of dealing with ruptured aneurysms.

We also believe that, for standard aneurysms, in patients at high risk with a hostile abdomen and appropriate anatomy, endovascular repair is best. In today's patient, because this particular gentleman's anatomy was so favorable, he would best be treated with an endovascular graft. He actually would have been fairly simple for an endovascular repair from the technical point of view.

As far as whether or not you should be subjected to liability for this particular case, I guess in the circumstances that exist in this country it is difficult for me to be conclusive. Certainly, in the United States if a patient were seen and had an aneurysm like this and weren't at least made aware of the fact that there were hospitals that could fix it, I think there might be some legal liability. We have had a number of patients who were told by their surgeons not to come to us for repair, and they took it upon themselves to do so, and they have been fixed successfully. Thus, many issues are raised by this case. I 
believe it would have been appropriate to at least let the patient know that an endovascular repair could be possible.

Modevator: There you have it. Straightforward anatomy, an investigative not an experimental technique, which might have been available had it been advertised. However, in the context of discussion, technology resource/allocation here is much more restrained than it is in the Bronx. Just as a straw poll as we go along, I am going to ask you where you think the liability lies. Let's suppose for the moment that Dr. Tanner had, in fact, plea bargained with Mr. Rowand, who is the President of this fictitious institution, about the desirability of having this equipment, but the decision had been made by the budget committee on which some of you sit that they weren't going to acquire the equipment. The fundamental issues here are, is Tanner liable? is the hospital liable? is the government of Ontario liable as the agent of the people, the accountability to the people for provision of timely service of reasonable quality? How many think at this point that Wayne is in some trouble? A few. How many think the hospital has a responsibility here? A few more. How many think the government of Ontario has a responsibility here?

The next speaker, and I can tell you a very effective speaker, I am happy to be speaking of is Scott. I wouldn't want to be in a court of law with him, though, because of his knowledge of the hospital procedures and responsibilities. Scott is a native of Edmonton. I got to know him when he was at Foothills Hospital at University of Alberta, then on the utilization committee for the government of Alberta. As some of you know, he came East and was the president of Wellesley, CEO, and turned that around and is now having an interesting time, I would say, in Hamilton, where he is the President and CEO of the Hamilton Health Sciences Corporation, which in combination now is one of the largest teaching health centers in Canada. That was effective in 1996. Scott has been a member of the faculty at University of Saskatchewan, University of Calgary, University of Toronto, and McMaster in a variety of capacities. He has been very active as a past President of both the Association of Canadian Teaching Hospitals and the Interior Counsel of Teaching Hospitals. He is currently a member of the Executive Committee, both teaching hospital group and ACMC. Scott is going to put on the hospital's case in this situation, what is the responsibility of the hospital in providing this kind of technology and available competent professional people for patients such as this?

$M r$. Rowand: Unlike Dr. Tanner, I live in the eye of the storm, so being a Christian in a den of lions, if not comfortable this is at least familiar. I participated in this exercise last year with the Canadian Cardiovascular Society, and so I am pleased to present the issue again today. Obviously, this mock trial is designed to consider an action in negligence for wrongful death, brought by the estate and family of the patient who died from this rupture. Obviously, the plaintiffs are arguing that the hospital and the doctors should be found negligent because endovascular surgery was not offered. 
I think the matter before us clearly points to the intersection of medicine, law, technology, and policy. Because it is a mock trial and I am on for the defendant hospital, it is my responsibility to offer perspective on the application of law to the facts in question, at least insofar as they apply to the hospital. There is an old maxim that, if the facts are against you, argue law, and, if the law is against you argue, the facts, and, if both are against you, then scream like hell. Fortunately, in this circumstance it is my view that the law is on the side of the hospital. I do have to say to you, though, that I think this is much more of a policy question than a legal question. So, having presented the legal arguments I'll conclude with a couple of comments on policy issues, with respect to emerging technology in the health care system.

To begin, the basics of negligence. To be successful it needs to be proved that a duty of care was owed to the plaintiff by the hospital or the doctor, that the hospital breached the standard of care established by law, that the plaintiff suffered injury or loss, and, that in this case, the hospital's conduct was both the actual and proximate cause of the patient's loss. So let me dispose of each of those issues, although in a slightly different order than I presented them.

Ultimately the patient's aneurysm ruptured, causing death; to suggest the plaintiff suffered loss is an understatement.

To the next issue, most candidates for surgery are worked up outside the hospital, although, as in this case, some hospital facilities were used for imaging and other specialized tests to arrive at a diagnosis, both of the abdominal aneurysm and comorbidity. The surgeon concluded that the patient was not a candidate for surgical repair and, therefore, was not placed on the hospital's waiting list. Clearly, hospitals under the Public Hospitals Act in this province and, indeed, in every other province in the country, don't admit patients. Patients are admitted by physicians. The patient was not yet a patient of the hospital and, indeed, not contemplated to be a patient of the hospital. Therefore, in my view from a legal perspective, there is no relationship between the hospital and the patient. So, I would submit that no duty of care was owed by the defendant hospital to the plaintiff and the action in negligence must fail on that test alone.

But I think that more interesting legal issues surround the standard of care owed by the hospital to its patients and the relationship of the actions or inactions of the hospital to the plaintiff's loss. With respect to the duty of care, it is established law in Canada that hospitals, or physicians for that matter, will be held to the standard of the skill, knowledge, and judgment of the average similar practitioner. Distinction of similarity has generally been defined around rural versus urban and specialists versus generalists. In this context, it is important to emphasize that it is the average-not the highest-standard of care, and it is against the reasonably expected standard in Canada, or in a Canadian community similar to the defendant hospital. There is no precedent that I can find in Canadian law in a medical malpractice matter where a Cana- 
dian hospital or physician has been held to a standard of care provided in another country. Minimally invasive endoluminal aortic aneurysm: now that's a mouthful for an administrator. I have to tell you, I spent the morning chairing a provincial committee on blood utilization. Today for me really is a circulatory system day. I understand this technology is not routinely available in Canada, even in Canadian teaching hospitals. It has been provided on compassionate grounds from time to time, but, except for what Dr. Scully indicated, there was no evidence that a request was made. So, he is changing the facts on me as we go along. Fortunately, Dr. Tanner's admission on that point is helpful.

We have a procedure or service not offered by the average Canadian vascular service. Thus, the defendant hospital is offering a standard of care that is consistent with the standard of care offered by other Canadian hospitals.

Obviously, the issue arises as to whether the patient should have been advised about what is available elsewhere; that has been spoken to, and, indeed, there is case law on that point. I would say to you that this is a duty imposed on the doctor, not on the hospital, because hospitals per se do not practice surgery.

Finally, for an action in negligence to succeed against the defendant, the plaintiff has to prove that the defendant's actions or inactions were both the direct cause of the plaintiff's loss and sufficiently foreseeable. Clearly, a ruptured aneurysm is foreseeable and, given the patient's history, was predictable. Obviously, in a real trial, evidence would be adduced with respect to the incidence and prevalence of aortic aneurysm, the likelihood of rupture, the impact of risk factors and operative mortality, and so forth. But, with respect to causation, the central questions for the court revolve around the appropriateness of the assessment of risk factors, the decision to not submit the patient for surgery, and, of course, the failure to inform the patient of other alternatives. I would submit that nothing that the hospital did do, or did not do, with respect to this patient was the direct or proximate cause of the patient's loss. After all, these are judgments in the control of the doctor, not the hospital.

It could be argued that the plaintiff was actually acting as an agent of the hospital. Physicians in Ontario, indeed in Canada, are granted an appointment and privileges; they are not in what is known a master/servant relationship as are hospital employees; and, therefore, doctors are liable for their own negligence. In the case of nurses and hospital employees, a hospital employee can be negligent, and the hospital will be found liable. So, the independent contractor status of the surgeon effectively shields the hospital from the doctor's liability.

I have argued the law as it applies to hospitals, but I think the central issue behind all of this is a policy decision not to offer novel forms of treatment that are made possible through technological advances. I think, as I said, this case is much more a policy question than a legal one. A court confronted 
with a question framed in tort law, in my experience and belief, would be loath to weigh in to the issues of distributive justice because all parties whose interests are affected are not before the court, in an action framed in tort.

We have lived through a decade of recession and heathcare fiscal restraints imposed by provincial governments. The cracks in the healthcare system are certainly beginning to appear. Even with sustained economic growth in Canada, which has been evident, and it is a very strong recovery and getting quite longstanding, there is an even larger crisis in front of us. That is the whole issue of demography. In Ontario, for example, leaving aside debt service, the Ontario government is now spending about $44 \%$ of its provincial budget on health care. About half those resources go to the $12 \%$ of the population over the age of 65 . In the next 15 years, that portion of Ontario's population will growth to about $20 \%$, and, if nothing else changes, it is predicted that healthcare costs will likely double. So, the very sustainability of our healthcare system, quite frankly, is in question. At the same time, as Hugh said, medical knowledge doubles about every 2 years. I'm one who believes that that technological advances that we've enjoyed over the last 20 years made the restructuring of Canada's healthcare system, which was absolutely necessary because of fiscal imperatives, possible. But, for advances in new drugs, minimal access surgery, advances in anesthesia, and so on, the changes that were needed to be made could not have been made without even more injury to access to care than we see today. It is clear to me that today, as a result of new technology, there are better outcomes and, in many cases, reduced cost. I also, however, can point to circumstances where the controlled diffusion of technology in Canada, compared with the United States, has served us well. There is much evidence around cost and outcome benefits in this country. The evidence is overwhelming that morbidity and mortality inversely correlate with experience in volume in many high-risk procedures.

We've got tough allocation decisions facing us, no doubt about it. But Canada's hospitals, physicians, and patients are falling behind in access to technology. I fear that this is going to get worse before it gets better. The current ratio, which is the ratio of current assets to current liabilities, usually used as quick measure of financial health, is below one for Ontario teaching hospitals; there are real and serious liquidity problems in the healthcare system. So, this doesn't look like a fertile environment for the introduction of new technologies.

This particular technology is an interesting one, as I understand it, because it represents a new cost in most instances, not a replacement cost. These are patients we wouldn't have operated on before.

I don't know what the answers are. I do know that malevolence is not at work. Governments, politicians, hospitals, physicians, and the public at large all share a common goal of the greatest good for the greatest numbers. I think targeting one another is never productive. But what stands between 
that objective and where we are today are enormous challenges, issues, and allocations decisions. I do know the courts are not the appropriate place to resolve these issues. I also believe that individual hospitals dealing with their medical staffs will not yield an answer that is sufficiently robust to address a universal Canadian problem. There is an important and urgent need, in my view, for an open and transparent public debate on the future of Canada's healthcare system, on how we ought to allocate resources, and how we can sustain our healthcare system. But, until then, the courts will deal with these issues on the basis of fact and law as we have known them. I fear that the risk will be predominantly shouldered by physicians. So, it is for this reason that I applaud Hugh Scully's efforts and those of the Canadian Medical Association to push this debate and to begin discussion on future healthcare because I think the profession has the most to lose. Thank you.

Modevator: Scott is not a lawyer, but he certainly knows the language very well. I think you would agree he is very articulate in presenting the situation and really describes the issue I think very strongly in the context in which we are all living. Increasing expectations, aging population (everybody over the age of 65 costs $\$ 8000$ a year, under 65 is $\$ 2000$ ), and he points out that the demographics point to an ever-increasing cost. So, it is a huge challenge for all of us.

With respect to our judge at the end of the day, one of the questions I would like to put out there just for thought is, should it be the case that physicians participate in resource allocation decisions? The law is quite clear that you cannot make the decision on an individual patient on the basis of cost. But the other issue that is out there, and one that causes some distress and as we get into the discussion later-I'll bring it back from the previous mock trial-is, should physicians be participating in allocation decisions? This has tremendous implications on availability and access. That leads to our next participant. The very interesting issue of the balance between rights, ethics, the law, and the Normal Society. Philip Hébert is going to talk about ethics and resource allocations. He is the Director of Clinical Ethics at Sunnybrook, Chair of the Research Ethics Board and the Sunnybrook Ethics Committee, and is an Assistant Professor in the Department of Family/Community Medicine at the University of Toronto. I think he will present some provocative thinking to you as we look at this issue of resource allocation.

Dr. Hébert: This case raises some of the more important and interesting issues medicine faces as it enters the new millennium. How ought new innovations in medicine be introduced? What ought patients be told about them? When do they become the standard of care? What about cost? Are the economic costs of new technologies a morally relevant factor? How ought scarce medical resources be fairly allocated? These are big questions that I cannot address in full today; I have been asked to concentrate on the latter issue. 
The bottom line is that clinicians and managers need ethical standards when it comes to making allocation decisions. This is to try to prevent avoidable harm from coming to patients and to ensure the resource decisions that are made are seen as fair ones. We may not always agree on the decisions that are made, but we should at least try to agree on a fair process for making them.

The case we are discussing today involves a seemingly avoidable death. The patient was not eligible for open aortic aneurysm surgery due to his high-risk state, and endoluminal AAA repair, a relatively new and expensive technology, was not readily available in his place of residence. He also died without even being informed that there was, possibly, another option for him. Was his death merely unfortunate or was it an avoidable death? Who, if anyone, is responsible? Of course, cases like this raise worries about misadventure. Did the patient receive less than he was due? What are the ethical considerations?

My brief answer to these questions-just so you know my answers in advance-are the following: First, his death was probably not avoidable because the procedure that might have helped him was too new to be routine. No one, of course, is responsible for his death-least of all Dr. Tannerbecause, in general, a surgeon can't control what and when resource-avid new innovations become available to patients. Did the patient receive due care? He received all reasonable care except maybe one thing - the whole truth. If a clinician knows of an option that might help a patient, he shouldn't wait for the patient to ask, he should be proactive and tell him of it. Of course, such options shouldn't be mere speculative possibilities or based on wacky science. The clinician's obligation to disclose alternatives wanes as the options get more remote and less tangible. The ethical considerations in this case pertain not just to resource allocation but also to disclosure.

Let's call a spade a spade. In the view of many clinicians, and likely the patient's estate now that they know of the option after his death, it seems that beneficial care was denied to a patient, at least in part, on the account of cost considerations. This certainly seems to be a "rationing" decision-limiting medically necessary care that could have prevented harm to a patient-and not just a "resource allocation" decision. The question is, are such compromises in care ever ethically acceptable? The brief answer to this question is, yes, they are at times unavoidable. I'm sure many of you would agree with this-as long as it doesn't affect my patients, right? So, when, you might ask, is it acceptable to limit care?

Allocating scarce resources can be a euphemism for rationing. Rationing means limiting access to, withholding, or not providing beneficial services to patients on account of nompatient-based factors. Usually, these factors are "third-party" concerns, either ones of cost to society or scarcity. Of course, if there is no benefit to patients from an option, then, in denying patients that 
option we are not talking about a rationing decision. Rather, we are simply talking about good clinical judgment, providing only care that will help patients. Patients may die because of illness that cannot be treated effectively. That is unfortunate, but it is not unfair and certainly not unethical and not an abrogation of any standard of care.

The first criterion an ethically acceptable resource allocation decision must meet is that of ensuring that nonbeneficial options are weeded out. We ought not to waste scarce resources on futile care, care that won't make a difference to outcomes. Morally speaking, this is the easiest cut to make when deciding what or what not to fund. Not allocating funds for patently nonbeneficial care is a no-brainer. What type of care is endoluminal surgery for AAA? One of three possibilities comes to mind.

Obligatory or necessary care is lifesaving care that should be provided as far as possible in a "just" healthcare system (e.g., dialysis for ESRD). Morally obligatory care is care that well-informed patients want, that achieves reasonable medical goals, and there is good evidence that it works, and that is not disproportionate in costs to what other patients receive. It is also the standard of care that a prudent practitioner would offer a patient.

Marginal care, by contrast, is care that is not necessary to extend life or prevent suffering. Either the goals are unimportant (e.g., liposuction) or there are other means to achieve the same end. Disproportionately expensive care, innovations for which there is poor quality evidence, and interventions not demanded by informed patients would also fit into this category.

There is, finally, also a category of inappropriate care-care that ought not be provided either because it has been shown not to work or has been shown to be harmful (e.g., anabolic steroids for athletes). I assume endovascular surgery does not fit in that category.

Part of the problem of resource allocation is new medical technology. The premature diffusion of a costly new technology has been identified as an ongoing phenomenon in medicine and can affect healthcare costs without improving patient outcomes. ${ }^{1}$ Innovative medical technology shouldn't be adopted simply because it is new; it ought only to be adopted when it has been shown to make a real difference to patient outcomes and when the cost is reasonable in relation to expected benefits. There ought to be a rigorous evaluation of any new technology before it is deemed to be "standard care" to which all patients should have access. Surgical innovations are sometimes introduced and widely adopted prior to the accumulation of such evidence. This is due to a number of factors such as the lure of the new, the pressure of the "technological imperative," financial incentives to introduce new forms of treatment, and defensive medicine, doing more than you ought to out of fear of being sued. The problem is that harm can be done to patients if professionals do not exhibit professional restraint in adopting innovations into clinical practice. ${ }^{2}$ 
This is the second principle of ethically acceptable allocation decisions: patients are due care that has been shown to work and make a significant, positive impact on clinical care. As a result, patients cannot expect to receive innovative care-being innovative it is not yet standard care. Innovations, especially new technologies of surgery, require sound evaluation before becoming the standard of care.

The question for the profession regarding this case is whether endoluminal surgery for AAA repair has reached the level of acceptability we accord to routine care. I suggest to you that it has not reached that level. Despite what we have heard today about its safety and efficacy, the evidence in its favor is mostly case series, and not evidence from randomized controlled trials. Thus, it is still "innovative," not yet standard practice, and so cannot be considered obligatory care. It certainly seems a step more than "marginal care"; it does show promise for some patients who have run out of options and are not content with a "wait-and-see" attitude. But, just because a patient has a potentially lethal condition and wants active treatment for it, it does not mean that society is obliged or able to provide such treatment.

In the good old days of modern medicine-its "golden" years-it seemed that funds were unlimited for medicine and clinicians could hope to satisfy all patient interests. One strong view of the traditional ethos was well expressed in this article a number of years ago in the New England Journal of Medicine by Norman Levinsky, entitled “The Doctor's Master". ${ }^{3}$ In this article, Levinsky argued that physicians are required to do anything and everything they believe may benefit each patient, without regard to costs or other societal considerations. This means the doctor could serve only "one master"-the patient-and, therefore, there are only two reasons to deny care, and they are, if it is no benefit to the patient or if the patient refuses the option. This is a rather uncompromising view-cost concerns are somebody else's business, not the physician's, and certainly not a bedside concern.

Since then, limited budgets and managed care have suggested a new ethos for medical care in North America that would change the ethical standard of care away from a purely patient-based one. What is the problem? Medical care offers more options but at ever greater expense. We may not be able to do everything we would like to do, that we might consider medically appropriate, because of the new fiscal reality. Hard choices may have to be made between competing claims for scarce resources.

The "tragedy of the commons," as it was called by Hardin over 30 years ago, is that small or "marginal" gains for some in society threaten the welfare of all. ${ }^{4}$ Thus, spending large sums of money to provide new and unproven technology to a few patients seems unfair if other patients fail to receive beneficial treatment backed by more robust evidence. Of course, in the case today, there was hardly a marginal loss to the individual because he died as a result, it is suggested, as a result of not receiving the new intervention. 
The question is then, is such rationing avoidable or not? There are pessimists and optimists in this debate. The optimists think that, even with limited budgets, if we do all the right things, such as funding only treatment backed by good evidence, or by being as efficient as possible, then there will be resources available to provide all truly helpful interventions. Pessimists, or, some would say, "realists," think that, even if we do all of the right things, then we still are not going to have enough resources to provide all helpful treatment. This latter view only means that the problem of justice is not going to be solved in any easy ways; there will always be a shortfall of resources and we will always be faced with making rationing decisions.

If the resources needed to sustain an intervention are truly scarce, rationing is, of course, unavoidable. This is particularly true in areas such as organ replacement therapy and battlefield triage medicine. An example of ethically sound rationing is what has been done in transplantation medicine where there aren't enough resources-transplantable organs - to meet needs. ${ }^{5}$ Despite this shortfall in resources, transplantation medicine, through UNOS, has tried to develop fair criteria for organ transplantation. These criteria are neutral ones, such as HLA matching, the likelihood of benefit to the patient from the available organ, the duration of that benefit, and the urgency or need of the patient for the organ. These are patient-based and evidence-based criteria that go some way to solving the justice problem in an area of medicine plagued by scarcity, by basing queuing for a scarce life-saving resource on objective criteria. These criteria do not go the whole wayas we know from other recent studies - that race, ethnicity, and sex still play a role in who gets referred for transplantation. This persisting inequity is recognized as a problem, however, and it is being worked on. In a "just" queue, patients line up for the scarce resource and get equal consideration based solely upon their interests.

This suggests a third principle to guide ethically sound resource allocation decisions. Where resources for patients are scarce, devise a mechanism for access that is fair and allows for due consideration of the interests of all patients.

This is where the differences in healthcare north and south of the 49th parallel come in. In Canada the healthcare system is supposed to provide "medically necessary care" to all citizens irrespective of a person's ability to pay. In theory, at least, a homeless person should have as ready access to coronary angioplasty or tPA as, say, a member of Canada's corporate elite. The provision of Canadian medical care is, supposedly, determined solely by the needs and preferences of patients. What UNOS has tried to solve in the United States for one area of medicine - transplantation medicine-is a problem for Canadian medicine as a whole. How can fairness of medical decision making in terms of who gets what services be ensured when we cannot provide everything to everyone just when they need it? Fairness can only be 
ensured if those responsible for the decision are vigilant about the welfare of patients who have to wait for care.

Research suggests that justice is always at risk of erosion, and subtle injustices can accrue around the distribution of care. In the Canadian Medical Association Journal in October 1999, an article explored factors affecting queuing and waits for cardiac catheterization. ${ }^{6}$ This is already quite a structured process; there are objective measures that should determine who needs and gets catheterization, so it, if anything, should be resistant to nonclinical factors. In fact, $10 \%$ of the variance as to who received this procedure was determined by nonclinical factors, such as which physicians the patients knew and which hospital they were admitted to. Surprising? Not really. Disappointing? maybe. But, is it any wonder that, faced with a scarce resource, clinicians might, after a while, "game" the system and try to get their patients treated first, even though such patients might need catheterization less than patients at the hospital across the street? What this points to is that fairness is not impossible, only elusive, and that we forever have to be vigilant about its erosion in the face of enduring scarcity.

A fourth principle for ethically acceptable allocation decision making is to ensure that the consequences of the decisions are monitored and continually reevaluated. Clinicians and managers must be vigilant to ensure that, say, when there is a queue and a death on a waiting list, that it was truly an unavoidable death, but that other equally needy patients were served by the queue.

Where clinicians have been particularly challenged ethically is by what has been called "bedside rationing" decisions. This is where known beneficial care is denied to patients for nonclinical reasons and the access to that care is under the control of the physician. Well, certainly that last condition would not hold in this case. The patient's surgeon, Dr. Tanner, did not make the decision not to provide AAA endoluminal surgery. By way of contrast, an example of bedside rationing would be, say, where a patient presents with a severe headache and the clinician who could order the MRI decides not to do so on account of cost concerns, despite thinking the MRI might be helpful. This type of bedside-rationing decision conflicts with the traditional ethical mooring of medicine in a patient-based, "best interests" standard of care.

To try to avoid such egregious ethical conflicts in care, I encourage you to follow the principles suggested by Dr. Hébert, which are always relevant and should help guide allocation decision making. ${ }^{\text {? }}$

Patient autonomy: Options for care and decisions about which treatments to fund and to provide to patients ought to reflect the wishes of informed patients. Patients, generally, studies show, tend to be more risk averse than physicians, whereas physicians tend to overvalue their interventions. Patients do not always want the newest technological intervention. Refusals of care by well-informed patients are, ethically, another acceptable way of allocating 
scarce resources. When in doubt about what patients want, ask them. They may not want "everything done."

Beneficence: If hard decisions must be made, care that extends life of a quality desired by patients is to be preferred to care that improves its quantity. Decisions about rank ordering care options ought to take into account the number of patients helped, the harm/benefit ratio of an option, and the quality of evidence concerning an option. As a principle, care that has been shown by the best-quality evidence to extend the life of a large number of patients, with little risk of serious harm, should receive priority over care that may improve the quality of life of a few patients and is only supported by preliminary evidence. Just what is a reasonable outcome, what is a reasonable benefit as regards an outcome, has to do with a risk-benefit assessment, which, often, only the patient can do. Clearly, this in part depends on the patient's values and preferences and, so, is partly subjective.

Best evidence: Care supported by evidence from robust randomized clinical trials with clinical outcomes valued by patients (death, quality of life) ought to be prioritized over care that is supported by only phase I or II trials and/or that uses nonclinical endpoints. As a principle, patients waiting for demonstrably beneficial care should not have their interests jeopardized to fund novel options of uncertain benefit.

Justice: Priorities for care ought not just reflect the needs of large numbers of patients. Patients suffering from rare but serious diseases deserve fair consideration of their needs as well. Because resources may always fall short of need, justice in health care can be best achieved by striving for a proper process of decision making. A proper process cannot always guarantee good outcomes for individual patients, but it strives to ensure that, when resources are in short supply, the decisions will be as rational as possible and free from bias and arbitrariness. The following factors, adapted from the UNOS experience (see: accessed June 21, 2000), seem most relevant to ensure this process is both fair and "smart."

Inclusive: Before making healthcare allocation decisions, decision makers should encourage participation by members of the affected population, by the public, and by other sectors of the medical community.

Multidisciplinary: Decisions about prioritizing care must be made by multidisciplinary committees that include, among others, representatives of the public, recognized experts in the field, experts in critical appraisal, and practicing clinicians.

Responsive: Decisions about care must be revisable and subject to regular review and be responsive to the latest known improvements in care.

Equitable: Decisions about care will take into account the needs and wishes of all patients and will be free of any discriminatory biases.

Open: Decisions about care will be made in a public and transparent way.

Mediation: Prioritizing decisions may be challenged by affected or concerned parties, and a review process will be established that involves independent mediators acceptable to both sides in the dispute. 
It is accurate to say that we do yet have fair processes in place to ensure just healthcare decision making. Our healthcare systems north and south of the 49th parallel have injustices built into them. The patient today got the best care that our currently flawed and ill-organized system could offer. His death could be a spur to get working on devising more just systems of care before other patients die.

Where patients get particularly discouraged is by the perceived lack of veracity from clinicians. Many studies have consistently shown that patients' informational needs are greater than for what physicians allow. Patients almost always want the information by which we make our decisions and recommendations for treatment. Patients are angered when they feel that important information about options has been kept from them. There is no reason one should not disclose to patients alternatives for care that, although perhaps not readily available or not yet the standard of care, are promising and perhaps available to the patient wishing to go to extraordinary lengths to get it. The system cannot be obliged to provide such options, for reasons dealt with already, but that doesn't erase the disclosure responsibilities of clinicians. The worry about so disclosing might be that of causing the patient needless anxiety or of falsely raising hopes, but these are risks, I think, that clinicians have to take.

Thus, the note I would like to end on is this: Justice must not only be done, it must be seen to be done. Even if this patient received all care that was his due, the fact that he was not informed about a potential option that he might have explored (or he might have turned down once told how preliminary it was) is perceived by the family as a lack of veracity and trustworthiness on the part of the clinician. It would have been better had this option been disclosed and it left up to the patient whether to pursue it or not. Is this a legal or a moral failure? Likely the latter, as I am not sure that this information would have induced him (or a reasonable Canadian person) to choose differently. If he had chosen differently, would the outcome have been any different? This is impossible to tell - he may have simply had bad disease and would have died anyway.

In summary, cases like this are made more problematic if clinicians don't disclose the alternatives. Clinicians don't have an obligation to do everything for patients because they don't have control over the resources. Clinicians are obliged only to do what is reasonable, which is determined by the standards of care in their country. There are principles and factors that should be taken into account by clinicians when making allocation decisions that can help ensure their ethical acceptability. Most important, we need a fair process to adjudicate competing claims for scarce resources and we need a rational social process, which we don't have as yet, to introduce new advances in medicine. Until we do, justice and fairness in health care will remain elusive. In the meantime, clinicians should be informing and involving patients and the public in their care. 
Modevator: I have been getting pleas from my immediate left for a chance at closing argument, on the part of the plaintiff. We have had as a presentation from the surgeon, an observation, and very good information about some of the leading-edge work that is going on with respect to treatment of aneurysms in difficult patients. We have also heard the hospital perspective; some of the ethical considerations about resource allocation in a country like this. I would suspect that one of the things we may get into is the locality principle; we are talking about Canada, Ontario, not the Bronx. That is an issue that is out there. I am going to break with protocol. Wayne, you've got 2 minutes to present some closing arguments, and then I am going to ask our judge to evaluate your liability, the hospital's liability, and the system's liability.

Dr. Tanner: I don't think my wife should empty those closets out quite yet. This boils down to was the care of this patient provided by myself acceptable and did it meet the community standard? Annually, in Ontario there are between 3000 and 4000 aortic aneurysm repairs. I don't know the exact data, but I would submit that annually in Ontario there are fewer than 100, perhaps fewer than 50, endoluminal repairs. Consequences of finding me guilty in this case would mean that every single person with an aortic aneurysm presenting to a surgeon will have to undergo, in addition to the CAT scan and ultrasound they have probably already undergone, an angiogram and a consultation by someone versed in endovascular techniques; only, I might say, to be put on a waiting list and to have about a 1 in 100 chance of getting it done. I believe that, if that was done with all of these patients, they would be subjected to the torture of a waiting list; there would be far more deaths on the waiting lists than there are presently. The torture that these patients endure, being given this false hope and being referred to a resource that we all know is unavailable, I believe is worse than the withdrawal of care, or the rationing of care as is currently done in terms of endovascular techniques. The consequences of a guilty finding in this case will drive up costs, do nothing to improve care, and, in fact, be detrimental to the thousands of aneurysm patients presently being very appropriately and successfully treated in this province.

Alternatively, we could send them all to the Bronx, and that is probably a subject for another debate. The next time I am speaking to Elizabeth Wittmer, I'll suggest that to her.

Moderator: How many think that Dr. Tanner has liability here? Has that changed? Fewer than before. Good closing argument. How many think the hospital has a responsibility? Very effective argument, Scott, about half the room. How many think the government of Ontario as the agent for the public has a responsibility? The majority of the room, as before. I am pleased to introduce to you Madame Justice Ellen MacDonald, who is with the Superior Court of Justice in the Province of Ontario. She has had experience as a trial judge on the issue of expert evidence. She was appointed to the Court in 
1991. She was educated at St. Dunstan's University, Charlottetown, PEI, and at McGill University in Montreal. Madame Justice, would you like to make some observations and tell us what the liabilities are?

Madame Justice: I am happy to be here. This is a novel experience for me because I am not in the company of either lawyers or judges. What I hope to share with you are some of my experiences that come from listening to very complex cases that are brought by plaintiffs in not dissimilar situations. The similarities are that the patients' families learn of a new technique after the event from the media or the Internet. The physician finds himself or herself faced with a lawsuit. The lawsuit gives rise to a debate on a number of issues that have been commented on by my fellow panelists this afternoon. I will deal with the easy matters first.

The Government of Ontario and the hospital, given the state of our current law, are likely to be not found liable in these circumstances. There are policy reasons why they are shielded from liability in the present state of affairs. I underline "the present state of affairs" because we are beginning to see a shift in the nature of legal arguments that are presented to us that indicate a shift of focus to both the hospitals and OHIP/the government as potential targets for liability.

I happen to be "current" on this topic because I am now considering these issues in a case over which I am presiding.

The reasons there is a movement in this direction will be obvious to you. One reason is that there is a tendency to look to these potential sources to respond to lawsuits because they are considered to be more deep pocketed. Nevertheless, both the governments and the hospitals are shielded from liability. One reason is, purely on the basis of contract law, what we refer to as the policy-making role versus the operational role. The government can say correctly, in my view, that it is involved in the development of policies that eventually translate into the actual decisions to make resources available that may permit certain treatments.

I turn now to the doctor. I do not see this as being an open and shut case. When one looks at it first, one can say, "Oh well, the doctor did not inform the patient about alternative forms of treatment; therefore, there is liability." But it is not so simple. The legal analysis is complex. As you have heard today, it involves a process of first establishing what the standard of care is; second, whether or not the standard of care was breached; and then, third, and most important, whether the breach caused the injuries. In other words, did the breach cause the death or was the death inevitable in any event or attributable to some other factor? Is the evidence such that a judge or a jury could determine, on the issue of causation, that the doctor could be found liable? It may seem strange to you (certainly it did to me when I first started working with these concepts), but the reality is that, on the issue of causation, a judge or jury listens for evidence that tips the balance of probabilities in favor of one side or the other. 
I can imagine what the debate would be if I were sitting as a judge in a real situation with facts similar to those discussed today. I would hear experts on both sides tell me reasonably and rationally why the doctor's decision was or was not a reasonable one in the circumstances.

This causes me to just say a few things about ways in which you can anticipate and probably protect yourself from potential claims.

First of all, good communication skills go a long way in preventing such claims or successfully defending them. Such skills are very difficult to achieve, particularly where time constraints are as extreme as they are. Then there is the more subtle issue, which is that, by the very nature of your specialty, you are dealing with issues that involve many "bad news" situations. Humanity is such that difficult news results in varied and difficult responses from patients. Based on what I have learned from your colleagues who testify in courtrooms, it is difficult to communicate effectively with the patient his/her options, especially because you, as the physician, can never know for certain if what you are saying is being understood.

My initial understanding was that Dr. Tanner did not inform the patient because the procedure was not available in Ontario. Dr. Tanner, I was uncertain, in your reply or sum-up, whether you were saying in effect, "Well, the procedure is available but it involves tremendous cost factors and other risks with the result that the procedure could not be rationalized for this particular patient."

Dr. Tanner: Procedures available in a very sporadic and underfunded fashion are not paid for by OHIP, and various institutions have, I hesitate to say experimental, so we will say investigational trials going on and they get money from wherever private source they can. Endovascular repairs are inaccessible as you can get. The numbers are 4000 regular repairs and I will say well under 100, probably 50, endoluminal repairs annually in the province.

Madame Justice: With that answer I would like to be able to say that I would have to think about it. This is how I would see the discharge of my judicial role. I would listen to what everyone has told me on both sides of the issue. The big concern would be that I might be imposing too high a standard of care on the doctor (given what Dr. Tanner has just told me) if I were to find that the doctor was negligent because he did not advise the patient and his family of the option of going to the Bronx.

Keep in mind that you have to look at this situation in the context of what is reasonable. It is not an ideal or perfect situation. This is one of the reasons the standard of care is always defined in terms of reasonableness.

If you take away anything from what I have said I would hope it would be that you can be comforted by the fact that the standard of care that is imposed upon you is one that is defined by reasonableness, having regard to all of the circumstances that you face.

Judges try to understand what the reasonable standard of care is and then reach a conclusion that defines the standard of care. This is, as most of you 
know, a time consuming and laborious process of hearing complex medical evidence.

In conclusion, I will say three things. Tort law has become costly, complex, and cumbersome. When I mention to you that I have just finished hearing a long case that touched on some of the issues that we are talking about today, I remind you that these cases are not out of the ordinary anymore. Second, we must begin to look at other ways of solving some of these problems simply because the resources on the judicial side are becoming compromised as well. Third, I wanted to share with you some observations about policy issues. This is obviously something that is not for the judiciary. Policy development is left to others.

Moderator: Thank you very much. I must say I wish you had been the judge in my other case.

The other case was one of unstable angina that had settled down; the patient was placed on a waiting list, was within the time frame of the waiting list, and unhappily, had an infarct and died at home. The surgeon and cardiologist were found liable on the basis of two things: (1) they ought to have known their patient better, which is a very difficult thing-the patient was monitored on a weekly basis - and (2) there had not been, notwithstanding the jurisdiction we're in, an effort to explain the availability of the Cleveland Clinic or the Mayo Clinic, or whatever, and an offer to act as an intermediary on behalf of the family should they choose to exercise that option. As a consequence of that I can tell you that in cardiac surgery, increasingly across the country, the American option I described is presented in every office visit, together with the suggestion that it would cost patients money. Increasingly in cardiac surgery people are requesting in writing from patients and their families that they choose to stay and wait on the waiting list. That is one of the things that is going on.

Let's open up to a few questions. Microphone 1 in the front, microphone 2 in the middle. I would like to ask Dr. Veith: I have a patient who has fairly deep pockets. He is about 80 years old, pretty good overall health, wellinformed. He has been on the Internet, and I think he would like to have endoluminal repair. Could I give him a figure, a number, of how much it is going to cost him to go down there and visit you and pay for airplane, hotels, meals, grafts, and hospital charges?

Dr. Veith: That is a very good question. We see a fair number of patients, not only for endovascular grafting but for other things. If everything goes smoothly, probably about $\$ 50,000$, considering the cost of a graft, if we had to buy one, the work-up, and all the other fees. The big problem is what if something goes wrong and we had an Indian religious leader who came to our institution and had a very complicated course? He also went to some other institutions in New York. I am terrified of finding out what the cost of that must have been, and I am sure constituency, which was quite numerous, 
had to come up with a fair amount of money. But, I would say $\$ 50,000$ should do it, if we had an uncomplicated course, or less maybe, in U.S. dollars.

Microphone 1: This is a question directed toward Mr. Rowand and perhaps Dr. Hébert. Endovascular grafts are available in Ontario now; it is not an investigational thing anymore, theoretically. What I don't quite understand from the hospital's perspective and perhaps as an ethical issue, in Ontario there are two centers, ours in Ottawa and London, that have been able to introduce this technology and start to use it. Why is that? Why should somebody in London have this available to them but not somebody in Toronto? Why should a surgeon in Toronto have to go through hoops to get their patients to London and hope we get the case done rather than say, "Well it is available in Ontario now; if it is available we have to be able to offer it." I am not quite certain how this technology is being introduced in Ontario in a reasonable and equitable fashion.

$M r$. Rowand: The reason it is available in London and Ottawa is because hospitals there decided to make it available and spend those resources on that technology rather than on something else. It is simply a matter of choice, and that goes to my point about these important decisions being made on a hospital-specific basis, which I think will not lead to a robust answer. In other areas of expensive, new, now a not-so-new technology, we have other examples. I think of pacemakers and more recently implantable fibrillators, where there is a funding vehicle for the graft itself, or the ICD technology. We do this in hips and knees and other kinds of things. Quite frankly, my counsel would be for the vascular surgeons of the province, if they believe this technology merits further diffusion, to begin to lobby the provincial government to treat this technology in the same way as other precedents exist in other fields of surgery.

Dr. Hébert: I think part of the problem is the inequity of geography in Canada. Certainly we have people away from large urban centers who do not get the same care as in an urban center; that is unfortunately a fact of life, but I agree with what Mr. Rowand is saying as well. I think it needs an appropriate and rational process for the introduction of new technology rather than having options varying from one practitioner and one hospital to the next.

Moderator: Let me comment for just a minute, on some of the discussion and just that kind of question. The position I have advanced on behalf of the profession is that not every hospital can have every bit of technology for any patient who wants it, or any surgeon or physician who wants to use it. We have a collective obligation as a profession, in my opinion, to concentrate centers of expertise and experience with some of the new techniques coming along. That is in the best interest of patients in terms of surgeons performing them frequently will get excellent results, as opposed to people doing it occasionally. Certainly, I can say on the cardiac side we are moving very aggres- 
sively on this connection. The best case in point that you all know about by reading in the newspapers, is a disaster that happens when a pediatric cardiac unit is not doing sufficient volume to meet a standard. It has to be concentrated in the hands of the few who are very good at it. I would suggest that in the development of vascular surgery the same thing applies, as it does in other areas.

Dr. Veith: Just so you realize that you are not the only ones who have problems, in the United States cardiologists have embraced endovascular technology in a way that I think is truly pitiful. They are advocating the correction of aneurysms of 3.7 to $4 \mathrm{~cm}$ in diameter. I have seen their notes. It is being done, and it is bad. They are also advocating such practice to their colleagues who have no experience with the care of aneurysms. Thus, maybe Canada is in some ways better than the Unites States. At least you don't have this problem.

Moderator: It comes down to the principle of what is in the patient's best interest, not in the commercial interest of the individual, the company, or the market.

Dr. Veith: In the United States there is also an explosion of available devices and new procedures, now that these devices have been approved, which I have considerable question about-an explosion for every vascular surgeon to do them, as well as the cardiologists, and I think these are not easy procedures to perfect. So, we have more than our share of philosophical and ethical problems in association with these.

Microphone 2: I would like your opinion. I am a vascular surgeon working in Quebec, and I have been involved in the creation of a new vascular service in Montreal, and unfortunately I have become quite popular. So, by last October/November I had 80 major cases waiting on my waiting list, including 30 to 40 carotid artery stenosis cases, and a couple of subtotal stenosis cases that I was not able to get in the operations schedule. One morning I had two patients in the emergency room suffering stroke and TIAs. So, I went all over the place-no complaint. I even called the Medical College, and the only answer that I was given, either by medical administrators or college officials, was, "Well, send them elsewhere." The only place where I could send these patients was to a surgeon whom I knew that had no waiting list, who I would not let operate on my dog! So, I settled the problem by closing my office. I don't see new patients. I have problems ethically with thatbecause doctors call me. They say, "Hey, I have a patient with severe ischemia." I say, "Okay, send him to Montreal." Am I correct? What do you think? What does the judge think?

$M r$. Rowand: I gather as a point of law in having read about just this issue, doctors closing offices, and how do you handle the fact that the general surgeons from Cornwall all take holidays at the same time. There is a problem when that kind of thing happens. You can talk to one another very clearly. If 
you're a specialist and somebody phones you about a patient and you respond quickly, and it is documented, make an effort to tell the person referring that patient that you are unable to see that patient, and make a recommendation for another referral, I think you are okay, apart from the discomfort that it creates for you. This is in the elective situation, not the emergency. Madame Justice?

Madame Justice: I think that is very correct. The obligation is to make referral elsewhere and that is the extent of it-as you said, you are recommending the patient be sent to Montreal.

Modevator: There is another issue that you bring up though; I won't talk about the vascular surgeon in the room because you are all equally competent. In the cardiac surgical area there used to be quite a variability in waiting lists. There was the issue that, if you had a long waiting list you must be a very good surgeon; if you have a short waiting list you don't-you are not a very good surgeon. That hasn't been borne out in a study over the last decade, monitoring the results of every surgeon, every year for every procedure for now 12 years. There are one or two exceptions. There have been no statistical outliers in the province among cardiac surgeons for that entire period of time. The results of coronary surgery are as good or better than anywhere else in North America, or the world, which is assurance to the public that the quality of coronary surgery by all the surgeons, long waiting lists or short, is equally good. So, one of the things you can do in vascular surgery to assure the public that the standard is there is to look at your waiting list and what it means, and how you are using the resources; it is not an easy thing to do, and it is tough because you get into personal sensitivity when you do that. Scott, did you want to comment on the resources to which some people can't get access because there is a long waiting list and others have short waiting lists - what should happen under those circumstances?

Mr. Rowand: It is an enormously difficult issue for hospitals. Again, it gets into the push and pull of politics within the institution. Assuming that people have fair and equal access to operating room time, for example (and that may be a big assumption depending on the hospital), but assuming there is a reasonable allocation process, that is probably as much as the hospital can do is to assure fairness. I worry in this province, for example, about what is going to happen in the fiscal year beginning April 1, if the province doesn't fund the nursing settlement and other settlements fully, and the cost of inflation. It is going to come out of patient volume and, by the way, your waiting lists are going to get longer, and your percentage of cases admitted emergently or urgently is going to grow as it has in each of the last several years of this decade. These are tough issues.

Microphone 1: Is it of value for the physician as an advocate of the patient's need, to have documented somewhere along the way, that some effort has been made to get that service available; that is, through the administrator, or 
through talk within the hospital? Like Dr. Tanner in the past, knowing about this technology, has shown some initiative, or is that important? Is it okay if he just sits back and says, "Okay, it's not available, it's none of my business"?

Moderator: We might again turn to Madame Justice. My understanding of that issue as we talked about this with the licensing authorities across the country, when it comes to allocation decisions, is that silence is in a sense complicit with rationing, if that is the active decision that is made. If you have articulated concern about that or legitimate technology that is known to work, and that is a matter of record, then you continue to be seen as a reasonable advocate on behalf of the reasonable expectations for your patients. That's the understanding we had in discussion.

Madame Justice: There is nothing I can add except to say that, in the context of this session, whether performance of a doctor was reasonable, one would be looking at what he or she knew and whether or not his or her conclusions are justifiably reasonable in the circumstances. It strikes me that, when you are assessing the doctor's decision, it is important that you keep in mind that we don't do it with hindsight in a sense that we don't apply the standards of what we know now. This is something I wanted to comment on. When I am told that medical knowledge is doubling at the rate of every 2 years I have to keep foremost in my mind that, when I am assessing a performance, I assess it in the context of what the state of knowledge was at that time. To me, if the doctor demonstrates that he or she formed conclusions about the appropriateness of that technology and whether or not it was "pie in the sky" and those conclusions were reasonable, that would be more or less the end of it. I hope I am answering your question.

$M r$. Rowand: I understand why you raised the point and the logical extension of this, being the administrator who received that letter, I would simply send it to the Ministry of Health and say "me too." We are talking about policy versus "operalization" of that policy; explaining the "doo-doo that flows downhill," principle and we are just simply reversing the flow in sending it out. It is not unlike a circumstance in which you have a number of patients booked for surgery in a given week and you have a more urgent patient and the operating room asks, "which patient are you going to cancel to do your urgent?" The same issue is for us administrators. Not being medical practitioners and, in fact, no medical practitioner being an expert in all fields, we rely on the medical advisory committee and other processes to make those policy judgments. If we do this, then what do we do less of? Hugh asked the question about whether physicians participate in allocation decisions. That's a tough one, but I believe our healthcare system would be very poorly served without the involvement of actively practicing clinicians at the front line making those key allocation decisions and participating in the debate providing informed opinions. 
Microphone 2: My name is Rod Seim. I do general and vascular surgery at a small community hospital in the west end of Ottawa. You are touching on what I was going to ask about. We are not worried about whether or not we can start an endovascular program. I chair Medical Planning and I will be attending an emergency meeting of AMC on Thursday to decide whether or not we will chop Plastics, ENT, and various other things along those lines. So, my question is, when I go to my constituents, the physicians, I ask them what role I should take, and many of them feel, "look, if you are going to be hanged there is no point in shooting yourself anyway." They feel we should back off completely from this, and if this isn't going to come to any resolution until this flows over completely into a public forum, much as it did with cardiac surgery 10 years ago when every night on the news for 3 weeks there was a lead item about another death or cancellation. So, I wanted to bring up that question again, and I would like to hear from other panel members and Dr. Scully and our Madame Justice about physicians contributing and what level they should do that.

Moderator: I agree with Scott completely that physicians who know a great deal about what is possible and what can be done need to participate in the decisions. Now, one problem that has come up often is that physicians in other quarters are targeted as the bad guys for either refusing to flex or bend, and my response to that, and very constructively with the discussions across the country, is to involve a broader constituency in the debate when it comes to deciding what services are going to be there. I don't believe it should be the physicians alone who make the decision about what is going to be cut, nor can it be the administration alone that makes the decisions, or the Board of Trustees that reflects the information that they get. If you are in a small community and services are going to be cut, it seems to me the community has to be involved in that discussion as well-because that becomes, among other things, a political issue of considerable importance. Frank, what happens in the United States? Everybody does everything?

Dr. Veith: No, we have a slightly different problem. One of the problems we face, and it is a terrible problem, is that we have a system called Medicaid, where the hospital gets paid, so they are taking on more Medicaid patients, and the surgeons don't get paid anything. Our administrators come to me as head of our service and say, "We've got to stop taking these Medicaid patients because we lose money." We can't pay the cost. So, this whole cost question is really a problem. I believe what is going to happen is we are going to end up with the old-fashioned system where patients will pay for almost all their care, and that would solve a lot of these problems. Get the government completely out of the healthcare business, but that's pretty radical.

Moderator: I would have to say up front that I disagree with you on that principle, but there is a wide range of opinion. 
Dr. Veith: We are clearly going to see two classes of medicine in the United States. We are going to see a private kind of care and insurance or managed care that is second rate. I think what will probably happen is that we will have the affluent patient getting the kind of care that he or she needs and the insured patient or indigent patient getting some form of second-rate or borderline care; that may happen here, too.

Mr. Rowand: Let me just echo what Frank is saying. I leave in a couple of weeks for a meeting of the Council of Teaching Hospitals of the Association of American Medical Colleges, and I go to that meeting every year simply to feel good, because, bad as it may be here, the teaching hospital system in the United States is in a lot worse trouble.

Moderator: To say to the doctor who is attending the MAC meeting next week, I think as a general principle my response to your comments would be that you are always better off being at the table than not at the table and if for no other reason that at least you can hear what they are saying about you.

Dr. Hébert: I agree. I think morally the physicians should be involved in this process because physicians certainly have the best knowledge of various procedures and various programs that may be cut or dwindled down, so it is very important to be part of that whole process. Otherwise, decisions will be made without any adequate medical supervision. At the same time you don't want to compromise your own professional judgment being part of a process that is according to dumb rational criteria. If they are willing to provide smart rationing decisions, then I think that is a process doctors would want to be part of.

Modevator: One of the cases I have made with government is that over the last decade and in large part across the country: physicians and leaders in nursing have not been involved in health policy planning as cuts have been made, and we are paying a huge price for that.

Dr. Hamilton (from the audience): One of the problems I find with communication is the little old man who comes to your office and when he dies 15 relatives show up afterward. Where are they in the forefront-is there any responsibility of those relatives to make an effort to go and hear what is said and ask the questions then because the little old man often can't ask the questions or doesn't know enough? The second issue is that person who is presented is going to die. We are all going to die. Who already has congestive heart failure, inoperable coronary disease; he's got a life clock that is ticking toward the end. Do you have a responsibility to him as vascular surgeons to also explain that he is going to die gasping for breath instead of dying quickly? What is our moral and ethical responsibility there?

I think as physicians we tend to be very protective of our patients. I don't think you should shield patients from bad news; on the other hand, I don't think you should wear the black hat every time a patient with bad coronary arteries comes into your office. So, I think you have to be judicious in terms of how you tell patients bad news, but I don't think you should be protect- 
ing people for fear that they may get upset with what you tell them. I think you have to lay cards on the table with patients who have very few options in front of them. If there is some option for them that might be available somewhere, which is very remote, I wouldn't think it was incumbent upon you to discuss it, but, if it is a new and upcoming procedure that might offer them some benefit, I think you should discuss it, even if the chance of the patient getting it is very small. In terms of relatives who aren't there, you can't do much about that. I think all you can do is assess the patient in your office and see if he or she is capable of really making competent decisions. If you think the patient is not fully conceding all the information then you may want to encourage him or her to bring someone else in to make these important discussions.

Moderator: That question is really an important one. We are running into that more and more. The most distressing thing is to have somebody transferred with unstable angina through the coronary care unit, come to the operating room, and not make it. When you phone the family, they say they are astounded, that he was only having a cardiac operation. What went wrong? What did you do wrong? The complacency that is out there is just phenomenal.

Dr. Veith: Now that the trial is over, I can say that I am not sure that we should do endovascular grafting on the high-risk patients either because in England and in Holland they are doing a randomized-prospective study comparing endovascular grafting versus no treatment.

I am not sure how it is going to turn out. Certainly with endovascular grafting one loses patients, and we get the same reaction-this is supposed to be a noninvasive procedure-how could you lose the patient? The other thing is that I don't think dying from an aneurysm is a very good way to go. The patients have a lot of pain, and they may linger for quite a while. There is no good way to die.

Modevator: Ladies and gentleman, I think we are at the end of our time, and on behalf of all of you I would like to thank all the members of the panel. Hopefully, you have enjoyed the exchange and the information.

Note

The "Mock Trial: Who Is Responsible for Access to Emerging Technology" was presented at the Toronto Vascular Symposium, April 7-8, 2000, Toronto, Canada.

\section{References}

1. Feeny D, et al. Health Care Technology: Effectiveness, Efficiency, and Public Policy. Ottawa, Canada: CMAJ Publications; 1986

2. Waring GA. Cautionary tale of innovation in refractive surgery. Arch Ophthalmol 1999;117:1069-1073

3. Levinsky N. The doctor's master. N Engl J Med 1984;311:153-155

4. Hardin G. The tragedy of the commons. Science 1968;162:1243-1248 
5. Benjamin $\mathrm{M}$, et al. What transplantation can teach us about health care reform. N Engl J Med 1994;330:858-860

6. Alter D, et al. Fairness in the coronary angiography queue. CMAJ 1999;161:813-817

7. Hébert P. Doing Right: A Practical Guide to Ethics for Physicians and Medical Trainees. Toronto: OUP; 1996 